\title{
Anti-Tubercular Activity of Silver Nanoparticle Synthesized from the Leaves of Murraya koenigii Linn and Fruit Peel of Punica granatum Linn
}

\section{Padmaa Paarakh*}

Department of Pharmacognosy, The Oxford College of Pharmacy, Bangalore, Karnataka, India

*Corresponding Author: M Padmaa Paarakh, Department of Pharmacognosy, The Oxford College of Pharmacy, Bangalore, Karnataka, India.
Received: February 08, 2020

Published: March 11, 2020

(C) All rights are reserved by M Padmaa

Paarakh.

\begin{abstract}
Medicinal plants have known to be the potential source for the treatment of many ailments. The present study is designed to investigate the in vitro activity of silver nanoparticle synthesized from the leaves of Murraya koenigii and fruit peel of Punica granatum against Mycobacterium tuberculosis H73Rv strain using Micro plate Alamar Blue Assay (MABA). The results revealed that the silver nanoparticle showed sensitivity against $M$. tuberculosis strain at a concentration $1.6 \mu \mathrm{g} / \mathrm{ml}$. The present investigation suggests that silver nanoparticles synthesized from the leaves of Murraya koenigii and fruit peel of Punica granatum possess remarkable antitubercular activity.

Keywords: Mycobacterium tuberculosis; Silver Nanoparticle; Murraya koenigii; Punica granatum; In Vitro; MABA; H37Rv
\end{abstract}

\section{Introduction}

Tuberculosis (TB), infectious diseases in lungs caused by $M y$ cobacterium tuberculosis affects the health burden in the world. In 2014 , nearby $80 \%$ of reported TB cases occurred in 22 countries and India has the largest number of cases, $23 \%$ of the global total [1]. In India, nearly $50 \%$ of patients are reported to be tuberculin test positive and one person dies from TB every minute [2,3]. However, Due to the usage of antibiotics, challenge of multidrug resistant TB has increased drastically. So, there is a need for discovery of new anti-TB drugs which are cost effective and safe. Medicinal plants have known to be the potential source for the treatment of number of diseases $[4,5]$. India has rich wealth of medicinal plants and usage of herbal medicines as traditional knowledge for curing several diseases is well documented $[6,7]$.

In recent years, the field of nanotechnology has potential applications for the development of novel technologies using metal nanoparticles viz., gold and silver which have several applications in sensors, detectors, and antibacterial agents [8-10]. Numerous chemical methods are available for synthesis of metal nanoparticles but the reagents used are toxic and potentially hazardous. Synthetic methods based on naturally occurring biomaterials provide an alternative means for obtaining these nanoparticles. Many researchers have achieved success in the synthesis of $\mathrm{Ag}, \mathrm{Au}$, and Pd nanoparticles extracted from plant parts, e.g. curry leaves, pomegranate [11], coriander [12] etc. In this regard, two plants viz., leaves of Murraya koenigii and fruit of Punica granatum were investigated.
In traditional system of medicine, the leaves of Murraya koenigii are used as tonic, stomachic, carminative, internally in dysentery, vomiting, anthelminthic, analgesic, cures piles, allays heat of the body, thirst, inflammation and itching. some notable pharmacological activities of the plant such as activity on heart, anti-diabetic and cholesterol reducing property, antimicrobial activity, antiulcer activity, antioxidative property, cytotoxic activity, anti-diarrhea activity, phagocytic activity and many more medicinal values have been reported [13].

Punica granatum is reported to have antioxidant, anticarcinogenic, and anti-inflammatory, focusing on treatment and prevention of cancer, cardiovascular disease, diabetes, dental conditions, erectile dysfunction, bacterial infections and antibiotic resistance, and ultraviolet radiation-induced skin damage, infant brain ischemia, male infertility, Alzheimer's disease, arthritis and obesity [14].

Hence, the present study is designed to investigate the in vitro activity of silver nanoparticle synthesized from the leaves of Murraya koenigii and fruit peel of Punica granatum against Mycobacterium tuberculosis H73Rv strain using Micro plate Alamar Blue Assay (MABA).

\section{Materials and Methods \\ Plant material}

The leaves of Murraya koenigii Linn and fruit of Punica granatum Linn were collected from local market in Bangalore, Karnataka, India and it was identified and authenticated. A voucher specimen 
[TOCOP/01/2017-18- Murraya koenigii and TOCOP/02/2017-18 -- Punica granatum] were deposited in The Oxford College of Pharmacy, Bangalore. The leaves and peel of the fruit were dried in shade and powdered coarsely, passed through sieve no. 40 and stored in air tight container for further use.

Preparation of extract

Coarsely powdered leaves of Murraya koenigii and fruit peel of Punica granatum 50g, each were boiled with $100 \mathrm{ml}$ of methanol for 30 minutes and filtered and evaporated to dryness. The percentage yield was found to be $1 \%$ and $3 \% \mathrm{w} / \mathrm{w} .0 .1 \mathrm{gm}$ each was dissolved and the volume was made up to $100 \mathrm{ml}$ with methanol. The solution is preserved for further use.

\section{Synthesis of nanoparticles}

- Chemicals: Silver nitrate was purchased from SD Fine chemicals Ltd, Mumbai. All chemicals and reagents used in this study were at least of analytical grade.

- Synthesis of Nanoparticles: A set of $1 \mathrm{mM}, 2 \mathrm{mM}$ and $3 \mathrm{mM}$ aqueous solution of silver nitrate were prepared for synthesis for silver nanoparticles [12]. Exactly $9 \mathrm{~mL}$ of each $1 \mathrm{mM}$, $2 \mathrm{mM}$ and $3 \mathrm{mM}$ silver nitrate solution was added to $0.1 \mathrm{~mL}$; $0.2 \mathrm{~mL} ; 0.3 \mathrm{~mL} ; 0.4 \mathrm{~mL}$ and $0.5 \mathrm{~mL}$ methanol extract of the leaves of M. koenigii and dried peel fruit of P. granatum to obtain silver nanoparticles. The different concentrations of silver nitrate and extracts were used to standardize the optimum concentration of silver nitrate and extract needed for synthesis of silver nanoparticles. The nanoparticles were synthesized at room temperature with $1 \mathrm{mM}$ silver nitrate with $0.3 \mathrm{ml}$ extract of each of 2 plant methanol extract and formation of nanoparticles was confirmed by checking $\lambda$ max using UV spectrophotscopy [15].

- Lyophilization Procedure for the Reluctant Sample Mixture: After the desired reaction period, the solution containing silver nanoparticles were lyophilized. The reluctant samples were centrifuged 10,000 rpm for 15 minutes. After 15 minutes, discard the supernatant and collected the pellet and freeze dried. The lyophilized samples were kept in the freezer at $4^{\circ} \mathrm{C}$ for further analysis.

- Characterization of Silver Nanoparticles: Ultra Violet visible spectroscopy analyses were carried out by UV-visible spectrophotometer Shimadzu in the range of $200 \mathrm{~nm}-800$ $\mathrm{nm}$, with the scanning speed of $100 \mathrm{~nm} / \mathrm{min}$. The morphology examinations of dried powder samples were analyzed with TEM analysis to check the particle size. The details analysis is already published by the author [15].

\section{Anti-tubercular activity}

The in vitro activity of silver nanoparticle synthesized from the leaves of Murraya koenigii [MLSSN] and dried peel of fruit of Punica granatum [PGDSN] have been evaluated against Mycobacterium tuberculosis H73Rv strain using Micro plate Alamar Blue Assay (MABA). This methodology is non-toxic, uses a thermally stable reagent and shows good correlation with proportional and BACTEC radiometric method.

Briefly, $200 \mu \mathrm{l}$ of sterile deionized water was added to all outer perimeter wells of sterile 96 wells plate to minimized evaporation of medium in the test wells during incubation. The 96 wells plate received $100 \mu \mathrm{l}$ of the Middlebrook $7 \mathrm{H} 9$ broth and serial dilution of compounds were made directly on plate. The final drug concentrations tested were 100 to $0.2 \mu \mathrm{g} / \mathrm{ml}$. Plates were covered and sealed with parafilm and incubated at $37^{\circ} \mathrm{C}$ for five days. After this time, $25 \mu \mathrm{l}$ of freshly prepared 1:1 mixture of Alamar Blue reagent and $10 \%$ tween 80 was added to the plate and incubated for $24 \mathrm{hrs}$. A blue color in the well was interpreted as no bacterial growth, and pink color was scored as growth. The MIC was defined as lowest drug concentration which prevented the color change from blue to pink. The drug Pyrazinamide was used as positive standard for comparison [16].

\section{Results and Discussion}

The UV visible spectroscopy showed $\lambda$ max at $460 \mathrm{~nm}$ confirming the formation of silver nanoparticles. TEM analysis showed that the average particle size was 17.44 and $22.02 \mathrm{~nm}$ for silver nanoparticles of M. koenigii and P. granatum respectively is already published by Padmaa., et al. [15]. Medicinal plants provide numerous examples of interesting secondary metabolites with antimycobacterial activity, indicating that natural products could be a helpful for the discovery of new anti- TB agents. Medicinal plants produce an excessive diversity of phytochemicals that could be active in medicinal field. There is an increasing demand of medicinal plants all over the world because the allopathic medicines have more side effects [17]. A diversity of methods has been developed to measure the sensitivity of M. tuberculosis. In present study the anti-tubercular activity was assessed by Micro-plate Alamar blue assay (MABA), using Alamar blue as the dye. The (MABA) Assay is a colorimetric oxidation-reduction based assay in which the Alamar blue dye accepts electrons and changes from the oxidized, non-fluorescent blue state to the reduced fluorescent pink state. In addition to mitochondrial reductase, other enzymes such as the diaphoreses, dihydrolipoamine dehydrogenase, quinone oxidoreductase and flavin reductase located in the cytoplasm and the mitochondria may be able to reduce Alamar blue reagent [18].

The anti-tubercular potential of silver nanoparticle synthesized from leaves of Murraya koenigii and fruit peel of Punica granatum are evaluated. The inhibition of the growth of M. tuberculosis $\mathrm{H} 37 \mathrm{Rv}$ strain at different MIC values is given in table 1 and figure 1 . A blue color in the well was interpreted as no bacterial growth and pink color was scored as growth. The qualitative visible change in color indicates on presence or absence of viable cells. The absorbance is measured at two different wavelengths (570 and $600 \mathrm{~nm}$ or 540 and $630 \mathrm{~nm}$ ). 


\begin{tabular}{|c|c|c|c|c|c|c|c|c|c|}
\hline Sl. No & Sample & $100 \mu \mathrm{g} / \mathrm{ml}$ & $50 \mu \mathrm{g} / \mathrm{ml}$ & $25 \mu \mathrm{g} / \mathrm{ml}$ & $12.5 \mu \mathrm{g} / \mathrm{ml}$ & $6.25 \mu \mathrm{g} / \mathrm{ml}$ & $3.12 \mu \mathrm{g} / \mathrm{ml}$ & $1.6 \mu \mathrm{g} / \mathrm{ml}$ & $0.8 \mu \mathrm{g} / \mathrm{ml}$ \\
\hline 1 & MLSSN & $\mathrm{R}$ & $\mathrm{R}$ & $\mathrm{R}$ & $\mathrm{R}$ & $\mathrm{R}$ & $\mathrm{R}$ & $\mathrm{R}$ & $\mathrm{S}$ \\
\hline 2 & PGDSN & $\mathrm{R}$ & $\mathrm{R}$ & $\mathrm{R}$ & $\mathrm{R}$ & $\mathrm{R}$ & $\mathrm{R}$ & $\mathrm{R}$ & $\mathrm{S}$ \\
\hline
\end{tabular}

Table 1: Result of anti-tubercular activity of silver nanoparticle synthesized from leaves of Murraya koenigii and peel of Punica granatum S: Sensitive; R: Resistance. Strain used: M. tuberculosis (H37RV strain).

MLSSN: Silver nanoparticles synthesized from M. koenigii; PGDSN: Silver nanoparticles synthesized from dried peel of fruit of Punica granatum.

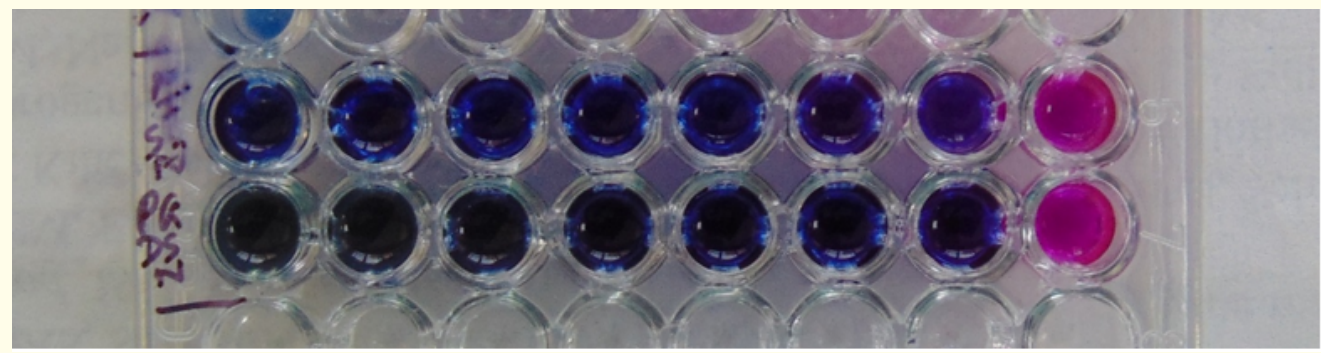

Figure 1: Anti-tubercular activity of Silver nanoparticles.

Silver nanoparticle synthesized had antitubercualr activity with an MIC value of $1.6 \mu \mathrm{g} / \mathrm{ml}$. The MIC values for standard were found to be Pyrazinamide $3.125 \mu \mathrm{g} / \mathrm{ml}$, Streptomycin $6.25 \mu \mathrm{g} / \mathrm{ml}$ and Ciprofloxacin $3.125 \mu \mathrm{g} / \mathrm{ml}$ respectively (Figure 2 ).

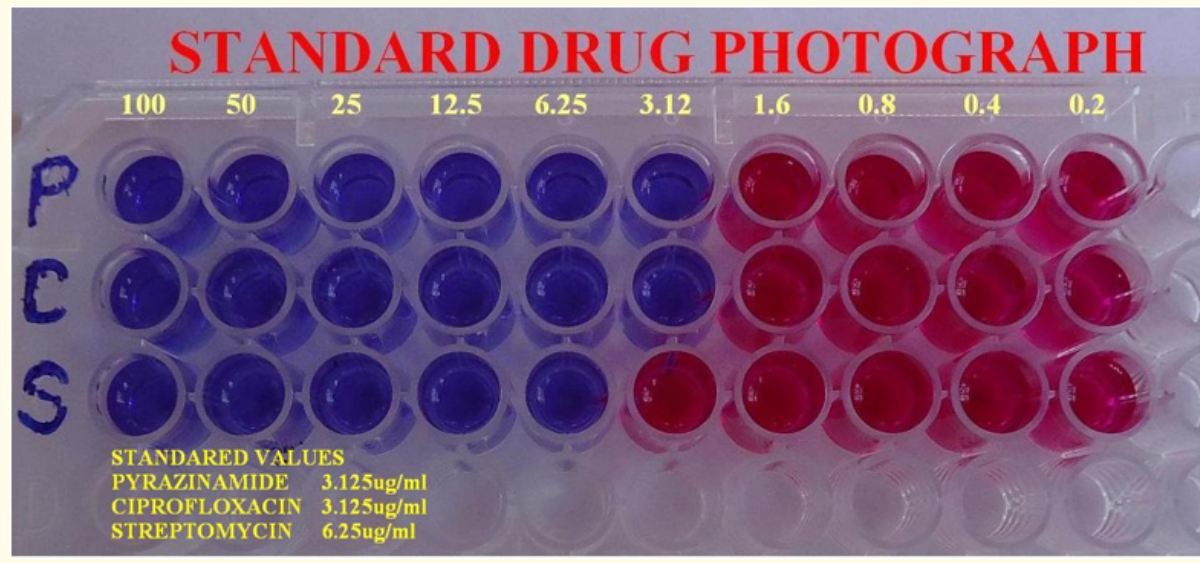

Figure 2: Antitubercular activity of standard drug.

MIC values of Pyrazinamide - $3.125 \mu \mathrm{g} / \mathrm{ml}$; Streptomycin - $6.25 \mu \mathrm{g} / \mathrm{ml}$ and Ciprofloxacin - $3.125 \mu \mathrm{g} / \mathrm{ml}$.

\section{Conclusion}

TB has become a serious infection as Mycobacterium tuberculosis develops resistance against both first and second-line anti-TB dugs. Due to this, there is an urgent need for novel anti-tuberculosis agents which should be sensitive. Hence, the present investigation concluded that the silver nanoparticle synthesized from leaves of Murraya koenigii and fruit peel of Punica granatum have shown anti-mycobacterial activity at different MIC values when compared with standard drugs such as pyrazinamide, streptomycin and ciprofloxacin.

\section{Acknowledgement}

The author is thankful to Children's Education Society [Regd.] and The Oxford College of Pharmacy, Bangalore for the facilities provided to carry out the study. The part of this study was done from the Research grants from Rajiv Gandhi University of Health Sciences, Bangalore which is highly acknowledged.

The author also is thankful to Maratha Mandal Dental College, Belagavi, (Dr. Kishore Bhat) for anti-TB activity and STIC, Cochin University for TEM analysis. The author acknowledge the work published in the International Journal of Current Medical and Pharmaceutical Research. 


\section{Ethical Issues}

There is none to be applied.

\section{Conflict of Interest}

None to be declared.

\section{Bibliography}

1. WHO. Global Tuberculosis Report, 20th ed. (2015).

2. Dhingra VK., et al. "Health care seeking pattern of tuberculosis patients attending an urban TB clinic in Delhi". Journal of Communicable Disease 34.2 (2002): 185-192.

3. Singh MM. "Tuberculosis-Triumph and tragedy". Journal of Indian Medical Association 101.3 (2003): 190- 194.

4. David JN., et al. "The influence of natural products upon drug discovery". Natural Product Reports 17.3 (2000): 215-234.

5. David JN., et al. "Natural products as sources of new drugs over the period 1981-2002". Journal of Natural Product 66.7 (2003): 1022-1037.

6. John MG., et al. "Activity of bromhexine and ambroxol, semisynthetic derivatives of vasicine from the Indian shrub Adhatoda vasica, against Mycobacterium tuberculosis in vitro". Journal of Ethnopharmacology 50.1 (1996): 49-53.

7. Gupta KC., et al. "Anti-tubercular action of Adhatoda vasica (N. O. Aganthacea)". Indian Journal of Medical Research 42.3 (1954): 355-358.

8. Jain PK., et al. "Noble metals on the nanoscale: optical and photothermal properties and some applications in imaging, sensing, biology, and medicine". Accounts of Chemical Research 41 (2008): 1578-1586.

9. Hu M., et al. "Gold nanostructures: engineering their plasmonic properties for biomedical applications". Chemical Society Reviews 35 (2006): 1084-1094.

10. Dasary SSR., et al. "Gold nanoparticle based label-free SERS probe for ultrasensitive and selective detection of trinitrotoluene". Journal of American Chemical Society 131 (2009): 1380613812.

11. Padmaa MP., et al. "Green synthesis of nanoparticles using plant extracts of Punica granatum and Murraya koenigii -a review". European Journal of Biomedical and Pharmaceutical Sciences 5.2 (2018): 234-239.

12. Padmaa MP. "Green synthesis of silver nanoparticles using fruits of Coriandrum sativum Linn and its antioxidant activity". Journal of Natural Product Research 1.1 (2015): 19-22.
13. Harish H., et al. "A review on Murraya koenigii: multipotential medicinal plant". Asian Journal of Pharmaceutical and Clinical Research 5.4 (2012): 5-14.

14. Neelam A., et al. "Punica granatum: A review on pharmacological and therapeutic properties". Journal of Pharmaceutical Science and Research 3.5 (2014):1240-1245.

15. Padmaa MP., et al. "In vitro anticancer activity of silver nanoparticles synthesized from the leaves of Murraya koenigii against cancer cell lines". International Journal of Current Medical and Pharmaceutical Research 5.11 (2019): 4743-4747.

16. Maria CS., et al. "Evaluation of anti-tubercular activity of nicotinic and isoniazid analogues". ARKIVOC 15 (2007): 181-191.

17. Vikrant A. "A review on anti-tubercular plants". International Journal of Pharmaceutical Technology and Research 3.2 (2011): 872-880.

18. Sephra NR. "Multiple applications of alamar blue as an indicator of metabolic function and cellular health in cell viability bioassays". Sensors 12.9 (2012): 12347-12360.

\section{Assets from publication with us}

- Prompt Acknowledgement after receiving the article

- Thorough Double blinded peer review

- Rapid Publication

- Issue of Publication Certificate

- High visibility of your Published work

Website: www.actascientific.com/

Submit Article: www.actascientific.com/submission.php Email us: editor@actascientific.com

Contact us: +919182824667 